\title{
Aerosol emission of adolescents voices during speaking, singing and shouting
}

\author{
Dirk Mürbe ${ }^{1}$, Martin Kriegel ${ }^{2}$, Julia Lange ${ }^{2}$, Lukas Schumann ${ }^{2}$, Anne Hartmann ${ }^{2}$, \\ Mario Fleischer $\circledast^{1 *}$ \\ 1 Department of Audiology and Phoniatrics, Charité - Universitätsmedizin Berlin, Berlin, Germany, \\ 2 Hermann-Rietschel-Institut, Technische Universität Berlin, Berlin, Germany \\ *mario.fleischer@charite.de
}

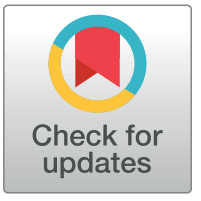

\section{Gopenaccess}

Citation: Mürbe D, Kriegel M, Lange J, Schumann L, Hartmann A, Fleischer M (2021) Aerosol emission of adolescents voices during speaking, singing and shouting. PLOS ONE 16(2): e0246819. https://doi.org/10.1371/journal.pone.0246819

Editor: Michael Döllinger, University Hospital Eriangen at Friedrich-Alexander-University Erlangen-Numberg, GERMANY

Received: October 26, 2020

Accepted: January 26, 2021

Published: February 10, 2021

Copyright: ๑ 2021 Mürbe et al. This is an open access article distributed under the terms of the Creative Commons Attribution License, which permits unrestricted use, distribution, and reproduction in any medium, provided the original author and source are credited.

Data Availability Statement: All relevant data are within the manuscript and its Supporting information files.

Funding: The author(s) received no specific funding for this work.

Competing interests: The authors have declared that no competing interests exist.

\section{Abstract}

Since the outbreak of the COVID-19 pandemic, singing activities for children and young people have been strictly regulated with far-reaching consequences for music education in schools and ensemble and choir singing in some places. This is also due to the fact, that there has been no reliable data available on aerosol emissions from adolescents speaking, singing, and shouting. By utilizing a laser particle counter in cleanroom conditions we show, that adolescents emit fewer aerosol particles during singing than what has been known so far for adults. In our data, the emission rates ranged from $16 \mathrm{P} / \mathrm{s}$ to $267 \mathrm{P} / \mathrm{s}$ for speaking, $141 \mathrm{P} / \mathrm{s}$ to $1240 \mathrm{P} / \mathrm{s}$ for singing, and $683 \mathrm{P} / \mathrm{s}$ to $4332 \mathrm{P} / \mathrm{s}$ for shouting. The data advocate an adaptation of existing risk management strategies and rules of conduct for groups of singing adolescents, like gatherings in an educational context, e.g. singing lessons or choir rehearsals.

\section{Introduction}

Aerosols are liquid or solid particles, which are transported in the air and not influenced by gravitation usually determined by a size less than $5 \mu \mathrm{m}$, that escape from the respiratory system during breathing, speaking and singing. Besides droplets, they are widely accepted carriers for the transmission of SARS-CoV-2 viruses [1]. Due to the principles of voice production and the described accumulation of SARS-CoV-2-infections during choir rehearsals [2], it is assumed that singing is connected with increased aerosol emission rates. Recently, increased aerosol emissions during singing in comparison to speaking have been experimentally confirmed for adult singers [3, 4]. Further, an increased aerosol emission rate is found for raising vocal loudness [5]. This results in limitations and specific risk management strategies especially for choir singing during the COVID-19-pandemic. However, data about aerosol emission during singing for adolescents are still missing. But especially for children and young people the restrictions on ensemble and choir singing have far-reaching consequences in addition to severe cultural and financial losses. Singing together is an obligatory part of school education and an important factor for the socio-emotional development of children and young people. This applies not only to music lessons in school, but also to the extracurricular sector with music 
schools and children and youth choirs. By now, the hygiene and performance concepts rely on aerosol emission rates during singing as collected from adults. For the first time, this pilot study presents data of aerosol formation when young people sing.

\section{Materials and methods}

Four girls and four boys, all 13 years old (except one girl aged 15 years), recruited in July 2020 by targeted call, participated in the study. They were members of a semiprofessional children's choir (Staats- und Domchor Berlin, Mädchenchor der Singakademie Berlin) and had perennial choir experience between five and nine years. All of them were before puberty voice changes, which was assessed by experienced choral directors. Apart from adolescent age, gender, perennial choir experience and pre-puberty voice status were no further inclusion criteria for this study.

The combination of adolescence and pre-puberty voice status allowed studying a representive group within boys' and girls' choir singers with advanced singing experience and cognitive development.

The study was conducted according to the ethical principles based on the WMA Declaration of Helsinki and was approved by the ethic committee of the Charité-Universitätsmedizin Berlin, Germany. Informed written consent was obtained from all subjects and their parents.

The investigations were carried out in a cleanroom (ISO-2-class) at the Hermann RietschelInstitute, Technische Universität Berlin, accessible through an airlock and equipped with terminal U15-filters.

To suppress the thermal plume at the subjects efficiently, the supply air in the whole cleanroom was introduced via a quasi-laminar vertical flow with a velocity of $0.3 \mathrm{~m} / \mathrm{s}$ (Fig 1) [6]. Further, the room temperature was $295.15 \pm 0.5 \mathrm{~K}$, and the relative humidity was $46 \pm 2 \%$. The static pressure in the cleanroom was about $20 \cdot(1 \pm 2 \%)$ Pa greater than outside the room.

In this highly pure environment, the subjects wore cleanroom clothing and a headgear to further reduce the clothing's particle emission. To perform the experiments, subjects sat in front of the test equipment, consisting of a glass pipe with a diameter of $295 \mathrm{~mm}$, through which a constant airflow of approximately $400 \mathrm{~m}^{3} / \mathrm{h}$ was generated by suction of a filter fan unit (FFU) (Ziehl-Abegg, Künzelsau, Deutschland) (Fig 1).

The vertical flow in the cleanroom and the glass-pipe construction ensured that emissions from other people (instructor, technical staff), who were necessarily in the cleanroom during measurements, were not directed to a laser particle counter (LPC) (Lighthouse Solair 3100 E, Lighthouse Worldwide Solutions, Fremont, CA).

The sampling probe $(37 \mathrm{~mm}$ ) of the LPC was placed centrally in the pipe. To reach a homogenous particle distribution at the measurement position, two baffles were inserted in the pipe to achieve a sufficient mixing of the particles at the sample point (Fig 1). The position of the LPC within the tube was based on the precedent setup of the measuring system utilizing visual (with stage fog) and quantitative (with an aerosol generator) assessments.

The particle counter was counting with a sampling flow rate of $28.3 \mathrm{l} / \mathrm{min}$ with a measuring time increment of 10 seconds. The detected particles were assigned to six size classes $(>0.3$, $>0.5,>1.0,>3.0,>5.0,>10.0 \mu \mathrm{m}$ ) between $>0.3 \mu \mathrm{m}-25.0 \mu \mathrm{m}$.

According to ISO 21501-4, the counting efficiency for particles of the size $0.3 \mu \mathrm{m}$ was 50 $\pm 20 \%$, and for particles of the size $0.5 \mu \mathrm{m}$ was $100 \pm 10 \%$. An initial baseline measurement showed a count rate of $<1$ particles for 5 minutes. Between the trials and tasks, a time increment of 20-30 s and 60-90 s, respectively, was chosen to avoid remaining particles of the previous task. This was confirmed by the display of a zero count at the LPC. 


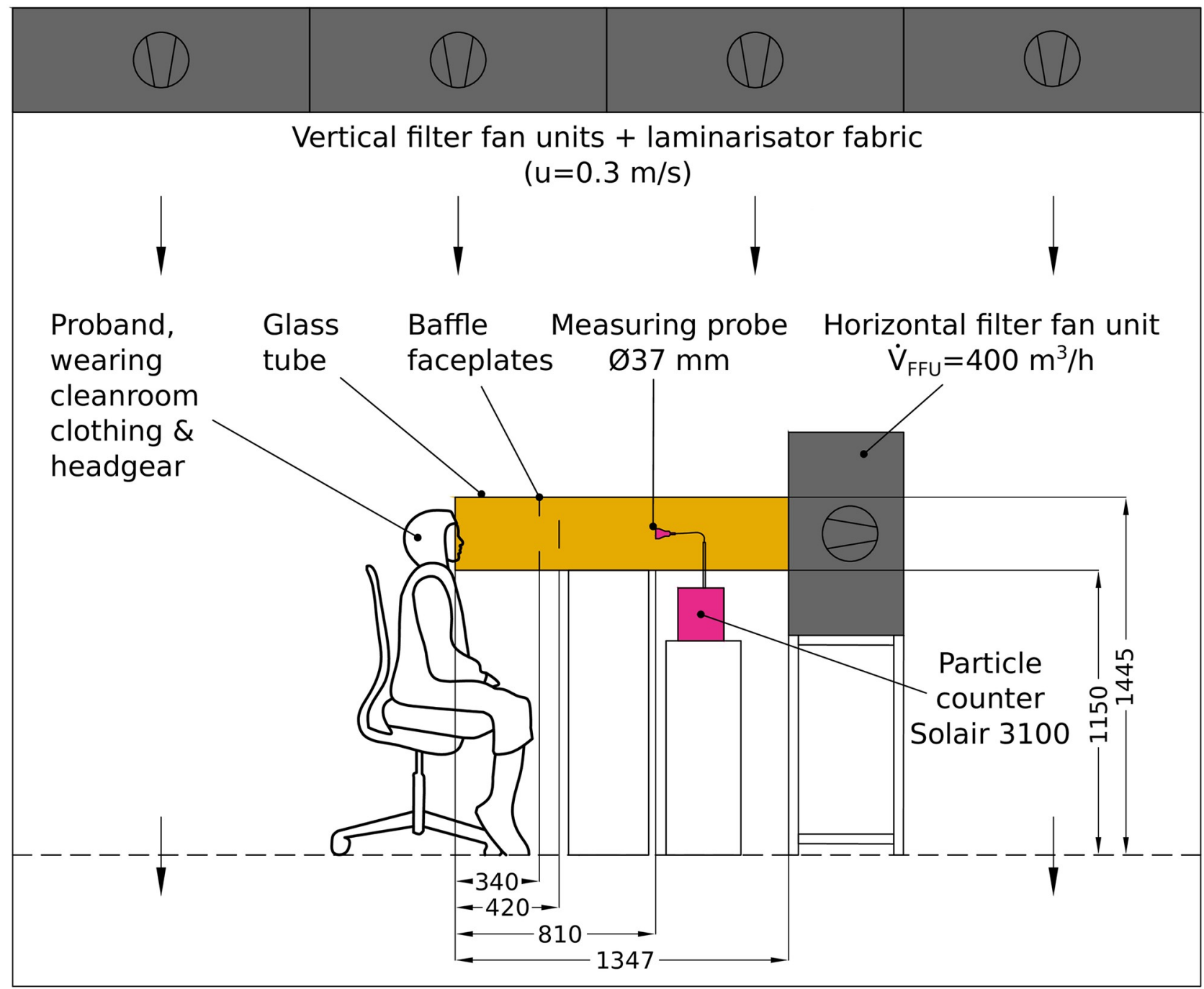

Fig 1. Experimental setup. The subjects sat frontal with their head at the free end of a glass tube (inner diameter $295 \mathrm{~mm}$, length of $1347 \mathrm{~mm}$ ) during the phonatory tasks. The suction side of a FFU that produced a horizontal volume flow of $400 \mathrm{~m}^{3} / \mathrm{h}$ on average was placed at the opposite end. To achieve a fully developed turbulent flow at the position of the LPC at $810 \mathrm{~mm}$, two baffle plates at distances of $340 \mathrm{~mm}$ and $420 \mathrm{~mm}$ from the entry were applied. All length units are in $\mathrm{mm}$.

https://doi.org/10.1371/journal.pone.0246819.g001

The emission rate $\mathrm{P}_{\mathrm{M}}$ was computed based on scaling of the particles measured at the LPC to the volume flow of the whole glass pipe. Apart from the particle measurement, the sound pressure level $\mathrm{L}_{\mathrm{AF}_{\mathrm{MAX}}}$ was measured via a calibrated sound level meter (CENTER 322_ Datalogger Sound Level Meter, Center Technologies, Houston, TX).

In the first task, the emission rates for three different vocal test conditions were compared: (a) speaking, (b) singing, and (c) shouting. Condition (a) was reading a standardized text ("Der Nordwind und die Sonne" by Äsop), a reference text for voice assessments with balanced phoneme representation. Condition (b) was singing the Swedish folk song "Vem kan segla" in key G-Major, a piece very familiar to the choir singers which could be sung reliably. For condition (c), subjects were asked to cheer enthusiastically about a soccer game goal. The time window for a measured sequence was 30 seconds for test conditions (a) and (b) and 10 seconds for test condition (c). Each test condition was repeated five times. 
In the second task, sustained phonation about 10 seconds was performed to investigate the impact of vocal loudness on the emission rate. Subjects were asked to sustain the syllable /la/, pitch G4 (392 Hz), at the two loudness conditions soft voice (piano) and loud voice (forte). To facilitate the 10 seconds measurement time, the young people were allowed to take a short breath within the recording and to repeat the syllable.

The emission rates were normalized to the respective time length of the tasks ( 10 or 30 seconds, respectively) and are time-averaged values.

Statistical analysis, individually handled for the two tasks, was carried out by using linear mixed-effects model (LMEM) analysis in the statistical software R (https://www.r-project.org/) including the package lmerTest [7]. This robust and flexible statistical framework was proven to have a high accuracy for multiple observations for numerous items [8]. For this study, logvalued $\mathrm{P}_{\mathrm{M}}$ data were incorporated as the response variable and condition as fixed effect. Further, intercepts for subject and by-subject random slopes for the effect of condition were regarded as random effects. P-values were obtained using Satterthwaite's degree of freedom method. The raw data of this study and the R-script containing statistical analyses are deposited in S1 and S2 Files.

\section{Results}

Within the measuring range between $0.3 \mu \mathrm{m}$ and $25 \mu \mathrm{m}$, about $99 \%$ of all measured particles for all test conditions were smaller than $5 \mu \mathrm{m}$ and more than $70 \%$ smaller than $1 \mu \mathrm{m}$ (Fig 2). With regard to the common understanding to denominate particles with a size smaller than $5 \mu \mathrm{m}$ as aerosols, the following results are cumulatively given for particles of size $0.3 \mu \mathrm{m}-$ $5 \mu \mathrm{m}$.

The emission rates $\mathrm{P}_{M}$ for speaking were clearly lower than for singing (Fig 3 ). Whereas the median values for speaking were between $16 \mathrm{P} / \mathrm{s}$ (Particles/second) and $267 \mathrm{P} / \mathrm{s}$, this measure was between $141 \mathrm{P} / \mathrm{s}$ and $1240 \mathrm{P} / \mathrm{s}$ for singing. For shouting, $\mathrm{P}_{\mathrm{M}}$ was still higher with values from $683 \mathrm{P} / \mathrm{s}$ up to $4332 \mathrm{P} / \mathrm{s}$. All subjects showed a clear individual increase in $\mathrm{P}_{\mathrm{M}}$ for all three conditions.

Linear mixed modeling showed, that these increases in condition were significant (likelihood-ratio test; $\mathrm{p}<.00001)$. On average, the ratio of $\mathrm{P}_{\mathrm{M}}$ between singing and speaking was 5.87 \pm 1.28 (standard error). For shouting and speaking, this ratio was $36.22 \pm 1.28$ (standard error).

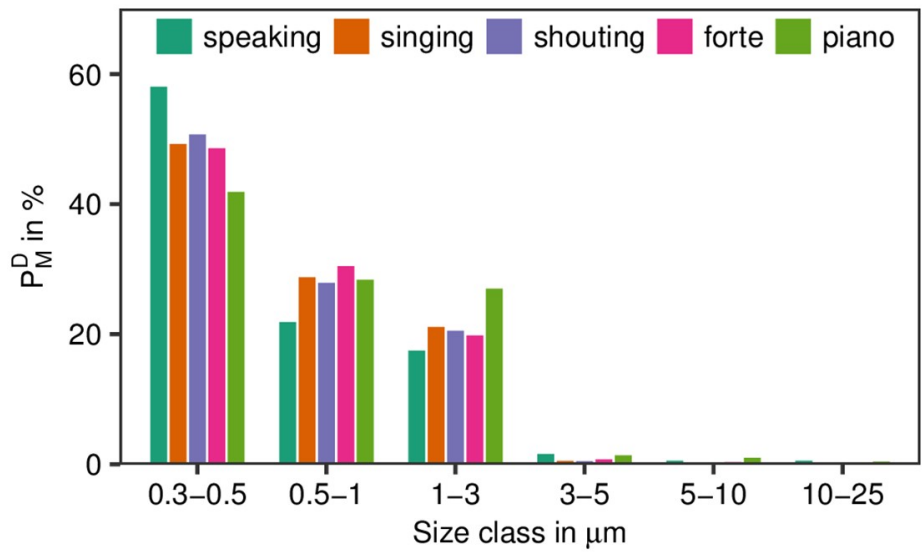

Fig 2. Size distributions. Distributions of emission rates $\mathrm{P}_{\mathrm{M}}^{\mathrm{D}}$ for different size classes and test conditions in $\%$. These

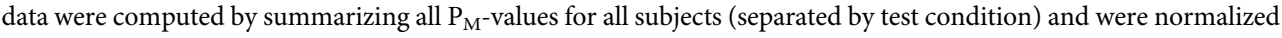
to the sum for all size classes dependent on test condition (see S2 File for details).

https://doi.org/10.1371/journal.pone.0246819.g002 


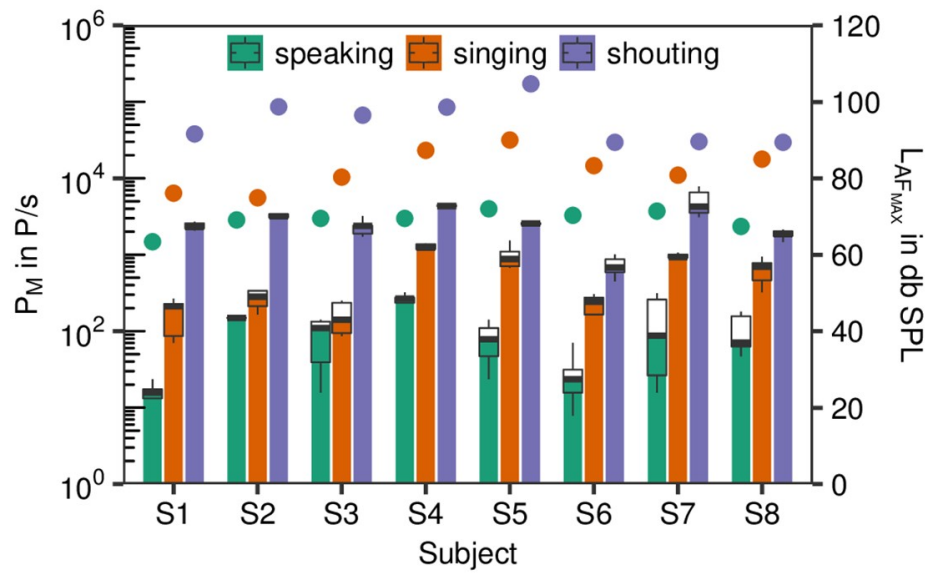

Fig 3. Emission rates. Boxplots of the emission rates $\left(\mathrm{P}_{\mathrm{M}}\right.$ in $\mathrm{P} / \mathrm{s}$, left $\mathrm{y}$-axis) for the test conditions speaking, singing and shouting for subjects S1-S4 (girls) and S5-S8 (boys). The maximum sound pressure levels $\left(\mathrm{L}_{\mathrm{AF}_{\mathrm{MAX}}}\right.$ in $\mathrm{db} \mathrm{SPL}$ ) are also shown (right y-axis) with different colored full circles for the test conditions.

https://doi.org/10.1371/journal.pone.0246819.g003

Both findings were significant $(\mathrm{p}<.001)$. Further, $\mathrm{P}_{\mathrm{M}}$ was positively correlated with the maximum sound pressure level $\mathrm{L}_{\mathrm{AF}_{\mathrm{MAX}}}$. An increase in one unit in $\mathrm{L}_{\mathrm{AF}_{\mathrm{MAX}}}$ resulted in an increase in 0.05 units of $\log _{10}\left(\mathrm{P}_{\mathrm{M}}\right)$. This finding was significant $(\mathrm{p}<.001)$.

For the sustained phonation task, the median values for soft phonation (piano) were between $58 \mathrm{P} / \mathrm{s}$ and $683 \mathrm{P} / \mathrm{s}$, this measure was between $58 \mathrm{P} / \mathrm{s}$ and $1907 \mathrm{P} / \mathrm{s}$ for loud phonation (forte). In contrast to the first task, not all subjects showed a clear increase in $\mathrm{P}_{\mathrm{M}}$ from piano to forte. This finding was mirrored by the results of the linear mixed modeling approach. The increase of $\mathrm{P}_{\mathrm{M}}$ from piano to forte was $1.91 \pm 1.47$, whereas the condition was not significant $(\mathrm{p}=.133)$. Nevertheless, a positive correlation to $\mathrm{L}_{\mathrm{AF}}$ wA was found (Fig 4), which indicates that the emission rate increases with raising vocal loudness. Similar to the first task, an increase in one unit in $\mathrm{L}_{\mathrm{AF}_{\mathrm{MAX}}}$ results in an increase in 0.05 units of $\log _{10}\left(\mathrm{P}_{\mathrm{M}}\right)$, which was also significant $(\mathrm{p}<.001)$.

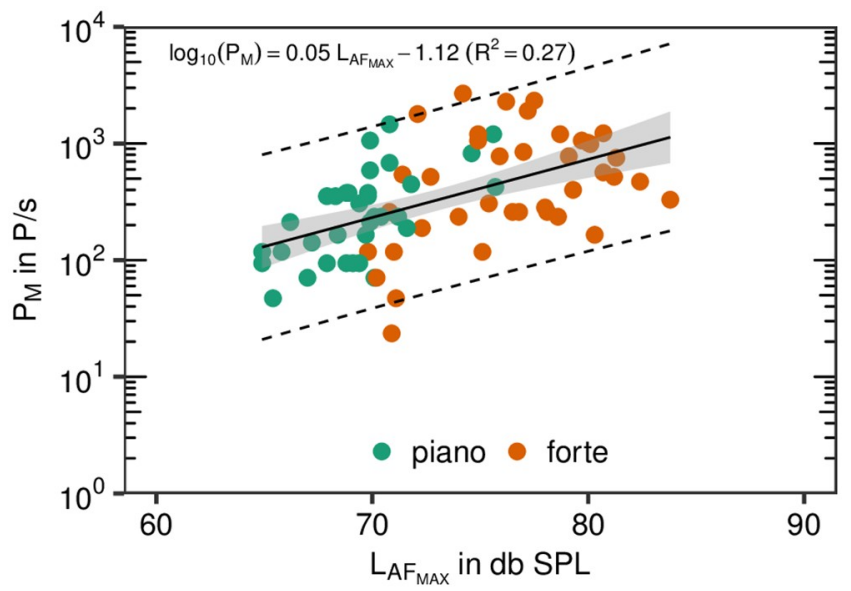

Fig 4. Emission rates vs. sound pressure level. Emission rate $P_{M}$ plotted over maximum sound pressure level $L_{A F_{M A X}}$ for sustained syllable /la/. All five repetitions for the two loudness conditions are represented by colored points as denoted in the legend. The black solid line represents the linear regression (see inset for details), the gray colored area represents the $95 \%$ confidence region, whereas the black dashed lines restrict the $95 \%$ prediction band.

https://doi.org/10.1371/journal.pone.0246819.g004 


\section{Discussion}

The present study confirms higher emission rates of aerosols for singing in comparison to speaking also for adolescents. As for measurements of adult professional singers, a strong intersubject variability of aerosol emission was found for singing adolescents, too. Finally, a positive correlation of particle emission with vocal loudness was confirmed, in particular reflected by the shouting condition. It should be noted that the results obtained must be viewed critically in terms of their transferability to a larger population. One limitation, for example, is that only a limited number of children and young people are active singers, who may differ in their singing techniques. In addition, the selection of the adolescents for this study is not representative of children and young singers in general in terms of the development of vocal skills and cognitive abilities during growing up.

Comparing these values with previously published data for adult professional singers [4] (http://doi.org/10.5281/zenodo.4011701) using the same experimental setup, similar values for speaking, but lower values for singing were observed (Fig 5). For singing, the ratio in medians between adults and adolescents was about 3.1. Shouting values for adolescents (not available for adults) were higher than singing values for adults. Regarding sustained phonation with loud voice, the ratio in medians between adults and adolescents for the forte condition was about 6.8. It must be noted that there were slight deviations between adults and adolescents in the execution of this task, such as adolescents were allowed to shortly breathe within the recording sequence. Except for shouting, determined values for adolescents are also lower than recently published data found in professional and non-professional adult singers [3]. In this study of 12 adult subjects, emission rates of $320-2870 \mathrm{P} / \mathrm{s}$ for singing at moderate to loud volumes are determined. On the other hand, Morawska et al. [9] reported values for 15 adults of 0.322 to $1.088 \mathrm{P} / \mathrm{cm}^{3}$ for voiced speech and normal speaking that can be approximately converted to emission rates by multiplying these values with a mean inhalation rate for males and females of about $9.5 \mathrm{l} / \mathrm{min}$ (see [10], p.18), to about 51 to $172 \mathrm{P} / \mathrm{s}$. In a comprehensive study with 48 adult subjects, Asadi et al. [5] found loudness correlated emission rates of 1 to $50 \mathrm{P} / \mathrm{s}$ for normal speech. Further, Gregson et al. [11] estimated also loudness dependent particle concentrations in the order of 0.1 to 1.3 and 0.19 to $2.47 \mathrm{P} / \mathrm{cm}^{3}$ (corresponds to an emission rate of about 15.8 to $391.1 \mathrm{P} / \mathrm{s}$ ) in a study with 25 adult subjects for speaking and singing tasks.

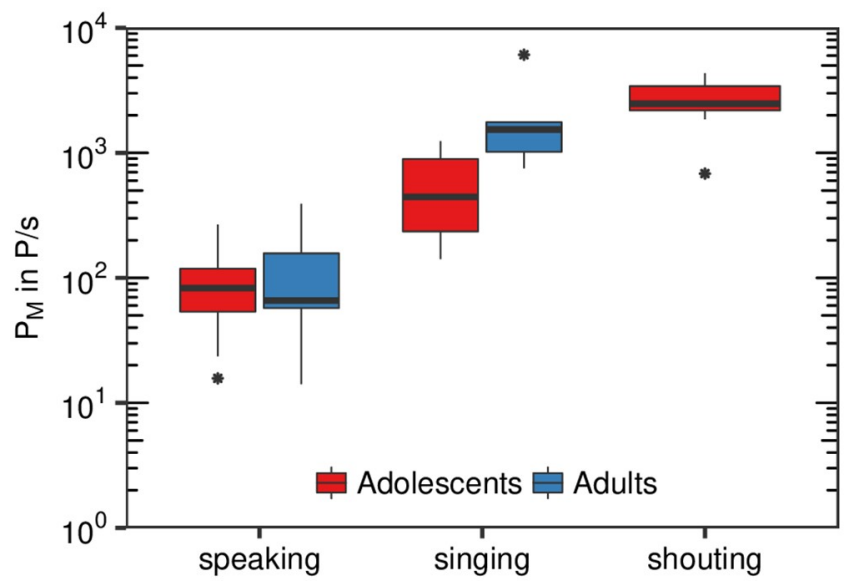

Fig 5. Comparison with data of adults singers. Boxplots of subject specific median emission rates $\left(\mathrm{P}_{M} \mathrm{in} \mathrm{P} / \mathrm{s}\right)$ for the test conditions speaking, singing and shouting (adolescents only). Present data of young voices $(n=8)$ in comparison with previously measured corresponding data of professional adult singers $(\mathrm{n}=8)(\mathrm{http}: / /$ doi.org/10.5281/zenodo. 4011701, see [4]).

https://doi.org/10.1371/journal.pone.0246819.g005 
Quite lower values for adults in the order of 0.0049 to $0.0215 \mathrm{P} / \mathrm{cm}^{3}$ (corresponds to an emission rate of about 0.8 to $3.4 \mathrm{P} / \mathrm{s}$ ) for talking tasks were also reported [12]. It can be summarized, that the adolescent's data for the speaking tasks presented here, are in the same order of magnitude than values reported earlier.

Regarding particle size distributions, it was found in several studies, that these distributions are mostly centered in a region of about 0.5 to $2 \mu \mathrm{m}$ for singing $[3,11]$, and 0.8 to $1 \mu \mathrm{m}$ for speaking $[3,5]$ and further skewed to smaller particle size. These observations were confirmed by our data for adolescents (see Fig 2).

There might be different reasons for the lower emission rates for child voices during singing. Before puberty voice changes, there are considerable differences in the vibration characteristics of the vocal folds in comparison to adults. Typical features of a child's vocal register in singing include differences in contact time and contact area of the vocal folds during each vibration cycle. There are also differences in the subglottic pressure between adults in general and young people $[13,14]$. Further, there are smaller anatomical proportions of the child's airways and vocal folds are shorter before puberty voice changes. On the other hand, the fundamental frequency of the voice and accordingly the contact frequency of the vocal folds might be higher, especially in comparison with male adult voices.

Indeed, a major reason for the lower emission rates in comparison to professional singers might be the lower volume of the adolescent's voices during singing. This was especially evident in the task with intended loud singing, even if all subjects of this study had a longstanding choir experience. On the contrary, in the shouting condition, which is not related to limitations in the child's singing technique, some adolescents reached higher emission rates than adults during loud singing.

Our experimental setup uses a Laser Particle Counter (LPC) in cleanroom conditions (without a background concentration of particles) to assess the number and size of evaporated aerosols (or droplet nuclei) in their equilibrium state for different kinds of vocalisation. Estimating the precise number and size of these particles is of great interest to assess the concentration of those particles in closed rooms. Because of the great range of the exhaled air volume flow from zero (close mouth) up to at least 7.5-15 1/min for phonation [10, 15-17] and $24 \mathrm{l} / \mathrm{min}$ for blowing [18], the measurement setup must be both, highly sensitive to detect all particles and suitable to cover the whole volume flow range.

Thus, different considerations were included in designing the setup for this study. First of all, a filter fan unit with a high volume flow of $400 \mathrm{~m}^{3} / \mathrm{h}$ has been selected, whereas the flow of exhaled air is small and can be neglected. To further avoid any disturbances regarding stagnating flow at the measuring probe, this probe was positioned centrally in a glass pipe. Further, by placing a turbulence generating baffle between mouth opening and probe, there was a homogenous particle density distribution in the cross sectional area of the glass pipe. This in turn required the choice of an adequate distance between mouth opening and LPC, which was chosen to about $0.81 \mathrm{~m}$ and resulted in a traveling time of the particles of about $0.14 \mathrm{~s}$ in maximum (see [4] for details). These experimental conditions, including a relative humidity of about $46 \%$, result in approximately evaporated aerosols in their equilibrium state [19], which can be surveyed by the LPC with high accuracy and independently of the fluid flow at the mouth. Thus, the measured emission rates can serve as a realistic estimate for a possible carriage for viruses that propagate in the environment. Moreover, they allow a reliable comparison between the different vocalisation tasks. However, the emission rates reported in this study should not be interpreted as emitted droplets and aerosols directly at one's opened mouth [20]. Further issues with relevance for SARS-CoV-2-transmission during singing like the trajectory of larger droplets after emission from the mouth need to be studied with different methods like Particle Image Velocimetry or Phase Doppler Anemometry. 
For the assessment of the risk of SARS-CoV-2-transmission during singing, both, droplets and aerosols are considered as virus carriers. While virus transmission via droplets can be mainly handled by distance and hygiene rules, the risk management of transmission through virus carrying aerosols has to be addressed with further strategies [21-23].

Activities to reduce the aerosol input in closed rooms during singing include limiting the number of singers and the rehearsal or performance time, which contributes to a lower cumulative aerosol concentration. Apart from these issues, the individual emission rates of the singers determine the aerosol input into closed rooms. For singing, an increased rate of aerosol emission compared to speaking has been found for adolescents, too. The lower aerosol emissions for adolescents' voices during singing in comparison to adult singers might contribute to develop more specific risk management strategies for different constellations of singing. Apart from singing, adolescents' aerosol emissions during shouting may be even higher than adult's emission rates during speaking. That should be considered for risk assessments in the corresponding areas, too.

Further, risk management strategies should incorporate other approaches like room size and air condition systems, which will affect the number and the concentration of potentially infectious aerosols in the room, too. Especially modern mechanical ventilation systems might significantly lower the risk of aerogenic virus transmission [24].

Based on the current prevalence of the disease, advanced risk management for singing together for instance in music lessons in school should combine the above-mentioned tools. The findings for aerosol emission for adolescent voices should be especially used to specify rehearsal and performance schedules for children's and adolescents' choirs because of the significance of education and socio-emotional development for children and young people.

\section{Supporting information}

S1 File. Raw data. R-readable data frame. In addition to data for ID, condition, cumulative $\mathrm{PM}$, and SPL, the emission rates for the six size classes (C1-C6), corresponding to $>0.3-0.5$, $>0.5-1.0,>1.0-3.0,>3.0-5.0,>5.0-10.0$, and $>10.0-25 \mu \mathrm{m})$, are given. (CSV)

S2 File. Statistical analysis. R-script for running the statistical analysises of the data provided in S1 File.

(RMD)

\section{Acknowledgments}

We thank the girls and boys and the accompanying staff of the Staats- und Domchor Berlin and the Mädchenchor der Singakademie Berlin for their personal support, T. Nawka for general discussion, A. Rameau and two anonymous reviewer for their valuable comments.

\section{Author Contributions}

Conceptualization: Dirk Mürbe, Martin Kriegel, Mario Fleischer.

Data curation: Dirk Mürbe, Julia Lange, Lukas Schumann, Mario Fleischer.

Formal analysis: Dirk Mürbe, Mario Fleischer.

Writing - original draft: Dirk Mürbe, Julia Lange, Mario Fleischer.

Writing - review \& editing: Martin Kriegel, Lukas Schumann, Anne Hartmann. 


\section{References}

1. Morawska L, Cao J. Airborne transmission of SARS-CoV-2: The world should face the reality. Environment International. 2020; 139:105730 https://doi.org/10.1016/j.envint.2020.105730 PMID: 32294574

2. Hamner L, Dubbel P, Capron I, Ross A, Jordan A, Lee J, et al. High SARS-CoV-2 Attack Rate Following Exposure at a Choir Practice-Skagit County, Washington, March 2020. MMWR; Morbidity and Mortality Weekly Report. 2020; 69:606-610. https://doi.org/10.15585/mmwr.mm6919e6

3. Alsved M, Matamis A, Bohlin R, Richter M, Bengtsson PE, Fraenkel CJ, et al. Exhaled respiratory particles during singing and talking. Aerosol Science and Technology. 2020; 54(11):1245-1248. https://doi. org/10.1080/02786826.2020.1812502

4. Mürbe $\mathrm{D}$, Kriegel $\mathrm{M}$, Lange $\mathrm{J}$, Rotheudt $\mathrm{H}$, Fleischer $\mathrm{M}$. Aerosol emission is increased in professional singing; 2020. Available from: https://doi.org/10.31219/osf.io/znjeh.

5. Asadi S, Wexler AS, Cappa CD, Barreda S, Bouvier NM, Ristenpart WD. Aerosol emission and superemission during human speech increase with voice loudness. Scientific Reports. 2019; 9(1):2348. https://doi.org/10.1038/s41598-019-38808-z

6. Yang $\mathrm{C}$, Yang $\mathrm{X}$, Zhao $\mathrm{B}$. The ventilation needed to control thermal plume and particle dispersion from manikins in a unidirectional ventilated protective isolation room. Building Simulation. 2015; 8(5):551565. https://doi.org/10.1007/s12273-014-0227-6

7. Kuznetsova A, Brockhoff PB, Christensen RHB. ImerTest Package: Tests in Linear Mixed Effects Models. Journal of Statistical Software. 2017; 82(13):1-26. https://doi.org/10.18637/jss.v082.i13

8. Barr DJ, Levy R, Scheepers C, Tily HJ. Random effects structure in mixed-effects models: Keep it maximal. Journal of Memory and Language. 2013; 68(3):255-278. https://doi.org/10.1016/j.jml.2012.11.001

9. Morawska L, Johnson GR, Ristovski ZD, Hargreaves M, Mengersen K, Corbett S, et al. Size distribution and sites of origin of droplets expelled from the human respiratory tract during expiratory activities. Journal of Aerosol Science. 2009; 40(3):256-269. https://doi.org/10.1016/j.jaerosci.2008.11.002

10. Adams WC. Measurement of breathing rate and volume in routinely performed daily activities: final report, contract no. A033-205. Sacramento: California Environmental Protection Agency, Air Resources Board, Research Division. 1993;.

11. Gregson, Watson, Orton, Haddrell, McCarthy, Finnie, et al. Comparing the Respirable Aerosol Concentrations and Particle Size Distributions Generated by Singing, Speaking and Breathing. 2020; https:// doi.org/10.26434/chemrxiv.12789221.v1

12. Papineni RS, Rosenthal FS. The Size Distribution of Droplets in the Exhaled Breath of Healthy Human Subjects. Journal of Aerosol Medicine. 1997; 10(2):105-116. https://doi.org/10.1089/jam.1997.10.105

13. McAllister A, Sundberg J. Data on subglottal pressure and SPL at varied vocal loudness and pitch in 8 to 11-year-old children. Journal of Voice. 1998; 12(2):166-174. https://doi.org/10.1016/S0892-1997(98) 80036-2

14. Howard DM. Electrolaryngographically revealed aspects of the voice source in singing. Logopedics Phoniatrics Vocology. 2010; 35(2):81-89. https://doi.org/10.3109/14015439.2010.482863

15. Gupta JK, Lin CH, Chen Q. Characterizing exhaled airflow from breathing and talking. Indoor air. 2010; 20(1):31-39. https://doi.org/10.1111/j.1600-0668.2009.00623.x

16. Jiang JJ, Hanna RB, Willey MV, Rieves A. The measurement of airflow using Singing helmet that allows free movement of the jaw. Journal of Voice. 2016; 30(6):641-648. https://doi.org/10.1016/j.jvoice.2015. 07.018

17. Mittal R, Erath BD, Plesniak MW. Fluid Dynamics of Human Phonation and Speech. Annu Rev Fluid Mech. 2013; 45:437-467. https://doi.org/10.1146/annurev-fluid-011212-140636

18. Amis T, O'neill N, Wheatley J. Oral airway flow dynamics in healthy humans. The Journal of Physiology. 1999; 515(1):293-298. https://doi.org/10.1111/j.1469-7793.1999.293ad.x

19. Wei J, Li Y. Enhanced spread of expiratory droplets by turbulence in a cough jet. Building and Environment. 2015; 93:86-96. https://doi.org/10.1016/j.buildenv.2015.06.018

20. Chao CYH, Wan MP, Morawska L, Johnson GR, Ristovski ZD, Hargreaves M, et al. Characterization of expiration air jets and droplet size distributions immediately at the mouth opening. Journal of Aerosol Science. 2009; 40(2):122-133. https://doi.org/10.1016/j.jaerosci.2008.10.003 PMID: 32287373

21. Hartmann A, Mürbe $D$, Kriegel M, Lange J, Fleischer M. Risk assessment of rehearsal rooms for choir singing regarding aerosols loaded with virus; 2020. Available from: http://dx.doi.org/10.14279/ depositonce-10388.

22. Buonanno G, Stabile L, Morawska L. Estimation of airborne viral emission: quanta emission rate of SARS-CoV-2 for infection risk assessment. Environment International. 2020; 141:105794. https://doi. org/10.1016/j.envint.2020.105794 
23. Abuhegazy $M$, Talaat $K$, Anderoglu $O$, Poroseva SV. Numerical investigation of aerosol transport in a classroom with relevance to COVID-19. Physics of Fluids. 2020; 32(10):103311. https://doi.org/10. $1063 / 5.0029118$

24. American Society of Heating, Refrigerating and Air-Conditioning Engineers. ASHRAE Position Document on Filtration and Air Cleaning. ASHRAE, Inc., Atlanta, GA; 2015. Available from: www.ashrae.org/ about/position-documents. 